\title{
BRASIL E MOÇAMBIQUE: GEOPOLÍTICA, MODERNIZAÇÃO DA AGRICULTURA E FOME: MOTES DA EXPANSÃO DA FRONTEIRA AGRÍCOLA MUNDIAL
}

\author{
BRAZIL AND MOZAMBIQUE: GEOPOLITICS, MODERNIZATION OF AGRICULTURE AND HUNGER: MATTER OF THE \\ EXPANSION OF THE WORLD AGRICULTURAL FRONTIER
}

\section{RESUMO}

As experiências de modernização da agricultura no Brasil têm servido como suporte para o governo moçambicano propor mudanças substanciais no seu modelo agrícola e na estrutura de seu espaço agrário. Do mesmo modo que ocorreu no Brasil, Moçambique se torna um território disputado para servir à expansão da fronteira agrícola mundial. No caso específico de Moçambique, o discurso de eliminar a fome, dinamizar a economia, aumentar o PIB - Produto Interno Bruto, são corolários da empreitada geopolítica de grandes corporações internacionais dos EUA - Estados Unidos da América, Japão, China e Brasil para os fins modernizantes. Os trabalhos desenvolvidos por pesquisadores e estudantes brasileiros e moçambicanos, face a essa condição, estão sendo edificadas com base nas seguintes interrogações: por que o processo de criação de melhores condições de vida necessita de métodos violentos que corrói o regime coletiva de propriedade da terra? Até que ponto a "intenção modernizante" pode ser assumida e justificada como verdadeira? Trabalhos de campos, levantamento de fontes, organização de oficinas em Machambas moçambicanas, organização de simpósios no Brasil e Moçambique alimentam as pesquisas e conduzem às reflexões da relação entre geopolítica e modernização da agricultura em Moçambique.

Palavras-chave: Geopolítica. Modernização agrícola. Privatização corporativa das terras. Machambas

\section{ABSTRACT}

Experiences of modernizing agriculture in Brazil have served as a support for the Mozambican government to propose substantial changes in its agricultural model and in the structure of its agrarian space. As in Brazil, Mozambique becomes a disputed territory to serve the expansion of the world agricultural frontier. In the specific case of Mozambique, the discourse of eliminating hunger, boosting the economy, increasing GDP - Gross Domestic Product, are corollaries of the geopolitical endeavor of large international corporations in the USA - United States of America, Japan, China and Brazil for the purposes modernizing. The work developed by Brazilian and Mozambican researchers and students, in view of this condition, is being built based on the following questions: why does the process of creating better living conditions require violent methods that erodes the collective land ownership regime? To what extent can the "modernizing intention" be assumed and justified as true? Fieldwork, survey of sources, organization of workshops in Mozambican Machambas, organization of symposia in Brazil and Mozambique feed the research and lead to reflections on the relationship between geopolitics and modernization of agriculture in Mozambique.

Keywords: Geopolitics. Agricultural modernization. Corporate land privatization. Machambas

\author{
Eguimar Felício Chaveiro ${ }^{a}$ \\ Helsio Amiro Motany de \\ Albuquerque Azevedo ${ }^{b}$ \\ iD Ernesto Jorge Macaringue ${ }^{b}$ \\ Dernando Uhlmann Soares ${ }^{c}$ \\ ${ }^{a}$ Universidade Federal de Goiás (UFG), \\ Goiânia, GO, Brasil \\ ${ }^{\text {b } U n i v e r s i d a d e ~ E d u a r d o ~ M o n d l a n e ~}$ \\ (UEM), Maputo, Moçambique \\ c Instituto Federal Goiano (IFGoiano), Rio \\ Verde, GO, Brasil
}

DOI: $10.12957 /$ geouerj.2020.53910

Correpondência: eguimar@hotmail.com

Recebido em: 24 ago. 2019

Revisado em: 11 jan. 2020

Aceito em: 4 fev. 2020 


\section{INTRODUÇÃO}

Por meio de missões científicas, trabalhos de campo, visitas e reuniões com instituições gestoras do espaço agrário, tanto no Brasil quanto em Moçambique; orientação de trabalhos em nível de graduação, mestrado e doutoramento, elaboração de workshops e organização de colóquios científicos com participação efetiva de camponeses, no âmbito do projeto de pesquisa "Sementes crioulas, quintais agroecológicos e cooperação popular: troca de saberes e experiências de economia criativa do Cerrado brasileiro as savanas em Inhambane/Moçambique", financiado pela Coordenação de Aperfeiçoamento de Pessoal de Nível Superior - CAPES - decorre o presente trabalho.

Todas as atividades de espectro diverso envolvendo produção de textos, elaboração de diagnóstico, produção de acervos fotográficos e videográficos, basearam-se numa premissa: a modernização dos segmentos econômicos, detidamente, o da agricultura e do espaço agrário, tem sido apontada, tanto no Brasil como em Moçambique, como uma das prioridades do Estado. Pode-se dizer que as intervenções promovidas pelo Estado, em se tratando de Moçambique, mediante o Ministério da Agricultura e Segurança Alimentar (MASA), compreende o centro da política agrária atual.

A partir do foco da política de modernização ocorre a mobilização de recursos financeiros e toda a trama política com os organismos internacionais, como o Fundo Mundial de Investimentos (FMI), assim como o licenciamento de empresas; a prestação de serviços básicos necessários à cadeia produtiva; a definição das leis fundiárias; e a organização do trabalho.

Ao observar a documentação-base que define os objetivos da economia política oriunda da modernização, pode-se dizer ainda que o processo de formação econômica e social (FES) de Moçambique, passou por duas etapas históricas claramente distintas: a primeira se estendeu entre 1975 a 1990, e a seguinte, correspondente ao momento atual, teve seu registro a partir do ano de 2000. A década de 1990 é considerada neste trabalho, do ponto de vista das políticas econômicas, como sendo a de "estagnação", uma vez que as intervenções desenvolvidas no período se enquadram no âmbito de "ajuda de emergência".

Com essa periodização estabelecida não se pretende definir as etapas exatas e muito menos estabelecer uma comparação das políticas econômicas que deram e continuam dando origem à formação econômica e social (FES) de Moçambique. Nos últimos anos, e em particular de 2004 em diante, o processo de modernização da agricultura - e do espaço agrário, em Moçambique, foi apresentado como um projeto do Estado que objetiva transformar a estrutura agrária herdada da colonização.

A sua pertinência, de acordo com os seus promotores, se ancora em dois grandes objetivos: satisfazer a demanda nacional de alimentos e fermentar a produção de commodities agrícolas, fazendo da agricultura a 
principal fonte de matérias-primas, tanto para a subsistência no território nacional, como também para a exportação. No entanto, um fato característico desse processo é a violência social que o acompanha, dado que a fixação das empresas modernizadoras começa pela concessão de terra havendo sempre expropriações de terra de camponeses.

Diante dessa realidade, algumas perguntas se colocam: por que o processo de criação de melhores condições de vida necessita de métodos violentos que corrói o regime coletiva de propriedade da terra? Até que ponto a "intenção modernizante" pode ser assumida e justificada como verdadeira?

Com base no que tem sido reportado como resultados das intervenções levadas a cabo pelo MASA, consubstanciando-se nas narrativas que ocorrem durante a interação entre os membros do Governo moçambicano e as empresas estrangeiras, responsáveis pela modernização, tudo nos conduz a supor que, diante das condições concretas para realização da produção, formou-se uma ideia poderosa que destaca a necessidade de transformação da estrutura agrária. Modernização é a palavra mágica desse propósito.

O discurso de geração de altos níveis de produção e produtividade é - simbólico e ideologicamente repassado como a única forma de desenvolvimento do país. Essa ideia tornou-se uma espécie de verdade inquestionável. Nesse sentido, as quatro milhões de "explorações agropecuárias", que são efetivamente unidades de reprodução social existentes, cuja a maioria, isto é, cerca de 3,9 milhões correspondem às unidades produtivas de reprodução social familiar, devem estar adaptadas à lógica do mercado. Melhor dizendo: as unidades de reprodução social familiar, para que tenham capacidade de gerar maiores rendimentos, devem adotar o agronegócio como novo modelo de produção. Essa é a ideologia subjacente do projeto. A experiência brasileira de modernização, especialmente do território do Cerrado, é evidenciada como um modelo a ser seguido. Tratar-se-á desse processo.

\section{COOPERAÇÃO TÉCNICA: O DISCURSO DE DOMINAÇÃO}

Tornou-se imperativo, no atual projeto de modernização do espaço agrário e da agricultura moçambicana, a entrada de novos agentes, de modo que as atuais explorações agropecuárias que representam "médias unidades produtivas" se encontram presentes no controle de empresas. A palavra de ordem é: a produção agrária deve estar orientada para o comércio, ou seja, deve deixar de produzir comida para a população para transformar alimento em mercadoria e, assim, submeter-se às demandas do mercado mundial de commodities agrícolas.

Essas ideologias que já ganharam um corpo firme no seio do Governo foram construídas no âmbito da cooperação técnica bilateral. A cooperação técnica é uma experiência eurocêntrica, que emergiu no contexto 
de reconstrução do pós-guerra nos meados do século XX. No caso concreto dos povos que habitam o território de Moçambique, que nem se reconhecia o seu direito de autodeterminação, além de não se terem sido contemplados, tiveram de enfrentar as vicissitudes de dominação imperialista.

As experiências tecnológicas que hoje são expandidas para a periferia do capitalismo mundial foram criadas há mais de cem anos, e somente agora se observa a necessidade de sua localização em territórios africanos, onde nem a simples enxada de cabo cumprido, para não falar de trator, triturador, descaroçadora e carro de boi, existem nos espaços de vida das comunidades. Há que se estranhar esse fato, o que mobiliza a formular a seguinte questão: o que está por detrás da cooperação técnica?

O interesse consoante da cooperação técnica entre os países mais ricos do mundo e os países subdesenvolvidos, em particular, os da África Subsaariana, surge num contexto em que o sistema capitalista financeiro enfrenta uma das crises que perdura por muito tempo. A cooperação técnica não será uma estratégia destinada para encontrar formas alternativas que possam salvar os "rios de dinheiros" em risco de se "converterem em papéis simples" (Harvey, 2011)?

Do que foi acima argumentado pode-se dizer que a ideia de transformação da estrutura agrária corresponde a um projeto que pretende sujeitar a satisfação das necessidades familiares ao jogo mercantil. Ao vincular a produção familiar à lógica do mercado, significa entre muitas coisas, a especialização de bens cultivados; a produção de acordo com a demanda do mercado e a transformação de alimentos em commodities. Dado que, conforme apresentado, a atual estrutura agrária é majoritariamente composta por camponeses que produzem para a satisfação das suas necessidades por meio de produção de bens de consumo direto e de comercialização local. Por outro lado, a ação que se impõe é a conversão do camponês em agricultor, de tal forma que será capaz de cumprir com a nova missão - a de satisfação da demanda do mercado.

Para a consecução desse projeto geopolítico, pelo fato de a alteração pretendida acarretar custos e, não havendo capacidades internas, a estratégia adotada pelo Estado consiste no estabelecimento de alianças com o capital financeiro dos países mais ricos, de modo que se criem condições para viabilização da conversão pretendida. Tomando como ponto de observação o ProSAVANA - JBM, na figura 1, constata-se que há um estabelecimento de novos "limites de fronteira agrícola" mundial, com participação direta de Brasil e Japão que se configuram como indutores dos processos conducentes à "conversão", na primeira fase, dos camponeses inseridos na região Norte de Moçambique para agricultores em modalidade do agronegócio. 
Figura 1. Área de abrangência do ProSAVANA. Elaboração: MACARINGUE, Ernesto Jorge.

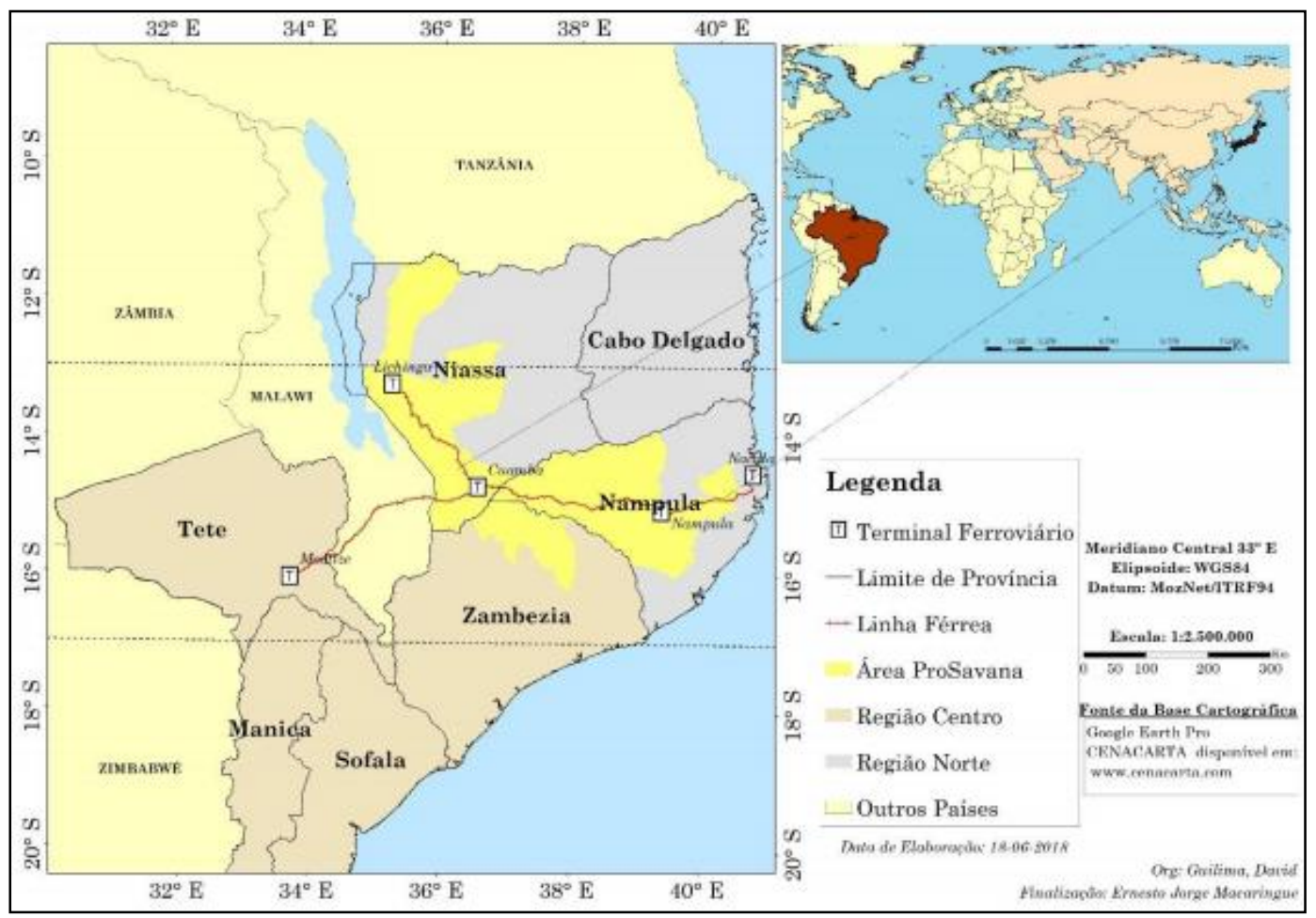

No conjunto dos processos impostos há que apontar as seguintes ações: realização de novas territorialidades cada vez mais robustas e vinculadas aos países indutores; inovações tecnológicas, com implicações nas relações sociais e nos modos de vida das comunidades originárias; inclusão e introdução de novos hábitos alimentares; alteração da estrutura fundiária etc.

O ProSAVANA - JBM enquadra-se no quadro dos programas e das estratégias do capital internacional, que usa o poder para estabelecer ações geopolíticas em "Estados frágeis", como é o caso do Estado de Moçambique, onde ainda se luta pela construção da "unidade nacional". A administração exercida no território nacional conta, em grande medida, com apoios externos diretos, em forma de donativos no orçamento do Estado. O país tem muitas limitações para ter acesso a créditos comerciais. Nesse sentido, o ProSAVANA - JBM é entendido neste trabalho como um instrumento do poder político, econômico, cultural e ideológico. Como instrumento do poder, as ações nele inseridas são impostas por meio de dispositivos estratégicos para apropriar e controlar territórios.

Ao se dizer que o objetivo do ProSAVANA-JBM está vinculado à melhoria das condições de vida da população, uma das questões que se coloca é: até que ponto se deve assumir que a vinculação do camponês à lógica do mercado, que exige especialização da produção, capacidades para concorrência, se constitui como condição para as melhorias prometidas? Ao se prestar atenção nas ações em curso, em particular ao processo 
de promoção, monitoria, fiscalização que são exercidas pelo MASA, depara-se com uma dificuldade para se estabelecer uma relação de casualidade entre os objetivos da política agrária e as intervenções concretas no território.

Um fato que nos chama atenção em Moçambique, e em particular, na região Norte de Moçambique, é que as narrativas que justificam a necessidade do ProSAVANA-JBM baseiam-se no objetivo de incrementar elevados níveis de produção e produtividade agrárias. Isso exige a ação de componentes técnicos avançados e o aumento das áreas de cultivo a serem asseguradas pela parceria público-privada.

Um desses projeto é o "Terra Segura" que, na fase "piloto", abrange apenas as províncias de Nampula e Zambézia, que na realidade fazem parte do Corredor agrícola de Nacala. Com esse projeto o Estado prevê proceder o registro de 5 milhões de parcelas ocupadas. Há um entendimento no seio do governo de que esse registro conferirá os respectivos Direito de Uso e Aproveitamento da Terra (DUAT's).

O projeto "Terra Segura" é entendido neste trabalho como uma etapa que antecede o ProSAVANA-JBM, e faz parte dos compromissos assumidos pelo Governo de Moçambique (GdM) no âmbito do novo modelo de desenvolvimento parceria-público-privado, inserido no Quadro de Cooperação do G8 para apoiar a Nova Aliança para Segurança Alimentar e Nutricional em Moçambique.

A titulação massiva é uma estratégia dos capitalistas, de modo que se contorne as barreiras enfrentadas na expropriação, como também para abafar as críticas que são atiradas às iniciativas do ProSAVANA, associadas aos novos conflitos de terras que emergem à medida que as ações planejadas são concretizadas.

Internamente as críticas são proferidas pela União Nacional de Camponeses (UNAC) como também por entidades de pesquisa autônomas, organismos da Igreja Católica (Comissão de Justiça e Paz da Arquidiocese de Nampula - CAJUPANA, Comissão Diocesana de Justiça e Paz de Nacala - CDJPN), Livaningo, Liga Moçambicana dos Direitos Humanos - LDH.

Por conseguinte, diante da demarcação e registro dos DUATs das terras de usos particulares dos agregados familiares, o projeto revela a falta de consideração pelos usos florestais coletivos. No plano externo, as vozes que criticam as iniciativas do ProSAVANA-JBM são do Fórum Mulher - Marcha Mundial das Mulheres, Justiça Ambiental (JÁ!) - Amigos da Terra Moçambique, GRAIN, Parlamento Europeu, tendo até solicitado, em 2016, a suspensão das ações inseridas na iniciativa da Nova Aliança para Segurança Alimentar em África.

Embora o projeto diz nominalmente tratar-se de mudanças de foco, o que ocorre é a mudança do sentido da estrutura agrária compreendendo as modificações do quadro legal, em particular, a lei de terra. Observa-se ainda a definição de uma nova política econômica, capaz de proceder alteração de uma herança 
histórica que deu origem às atuais formas de acesso e proteção dos direitos adquiridos sobre a terra, e, ao mesmo tempo, das relações de trabalho que prevalecem no campo.

Em Moçambique a atual formação social e econômica, que inclui a estrutura fundiária, as ações do capital privado e as infraestruturas são expressões, tanto da dominação estrangeira portuguesa, como dos programas de territorialização do capital. Um fato que nos chama atenção na estrutura social e econômica edificada, é que em todos contextos históricos os interesses dos camponeses foram subalternizados.

Mesmo sob pressão, as ocupações de "boa-fé" e outras formas de acesso à terra, recorridas pelos camponeses, em parte, contribuem para produção de novas territorialidades camponesas. Mas há que se reconhecer que algumas práticas consuetudinárias apresentam critérios que cristalizam exclusão de certos grupos, em particular, para mulheres e jovens.

Relativo à tecnologia, o país enfrenta o desafio de adoção de forças produtivas para a facilitação de atividades no processo de produção, de transporte, de armazenamento e de processamento de bens. Na província de Nampula, onde se estima que há cerca de 1.473.792 agregados familiares, cuja maioria está fixada no campo, as estruturas que administram o setor agrário afirmam que só há 25.000 enxadas de cabo cumprido e 53 tratores. Estes dados incluem os meios comprados no ano de 2015 (MASA, 2015). A figura 2 é representativa.

Como se vê nos dados e nas figura 2 e 3, os camponeses homens e, sobretudo, mulheres, de Moçambique, continuam submetidos às técnicas rudimentares, como é o caso do uso da enxada de cabo curto e às condições de armazenamento rudimentares, comprometendo a qualidade dos produtos e a capacidade de trabalho. Essas situações exigem que sejam repensadas as formas de redução do emprego intensivo sem que isso acarrete endividamento dos camponeses pelas instituições financeiras.

Figura 2. Camponeses revolvendo e adubando a terra com enxada de cabo curto em Inhambane, "terra da boa gente", província de Inhambane. Fonte: Autores, 2018.

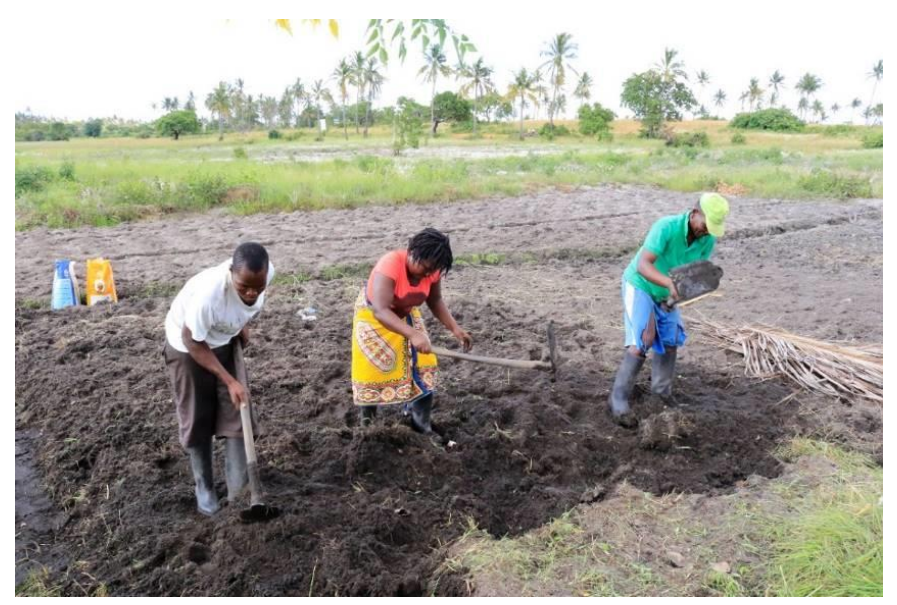


Figura 3. Mulheres camponesas na aldeia de Nocololo, Distrito de Monapo, Província de Nampula. Fonte: Autores, 2018.

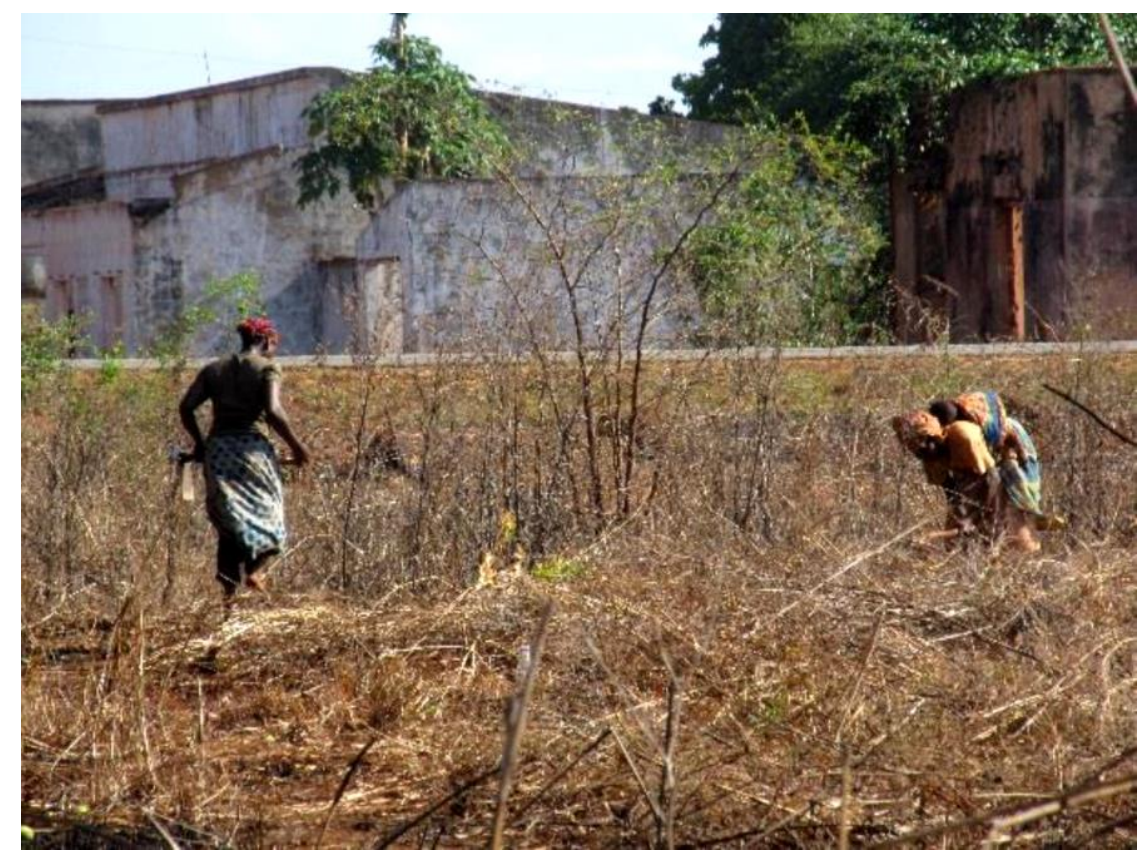

\section{MODERNIZAÇÃO DA AGRICULTURA: A PRÁTICA DE DOMINAÇÃO}

O termo modernização faz parte de um léxico cujo significado e sentido evoca uma progressiva transformação dos modos de compreensão. Em muitos casos aparece como resultado de inovações técnicas, que determinam as formas de realização da produção. Inclui também alterações na morfologia e no conteúdo do trabalho; nas formas de remuneração, na maneira de significar a terra e a natureza. É um conceito disputado: há uma visão liberal que o vê como instrumento do progresso, e outro decorrente de uma visão crítica, que interpela o seu conteúdo político e ideológico.

Mais que um simples termo, modernização é o processo de transformação da terra e do território, tal como assevera Santos (2013). As técnicas, em sua forma aparente são, todavia, apenas um vetor do espaço agrário. Tais técnicas não têm a mesma idade e, desse modo, pode-se falar do anacronismo de algumas e de inovação de outras. As técnicas agem em relações sociais concretas, em modos de produção concretos, por meio de relações materiais e simbólicas que as presidem. Isso nos conduz, sem dificuldade, a advogar que o entendimento das técnicas se subordina à noção de modo de produção e de relações de produção (SANTOS, 1979, p. 57). Por isso, modernização não pode ser sinônimo de avanço ou de inovação técnica.

A história das técnicas, tal como nos revelam alguns autores, é de transformações tecnológicas que implicam certamente em mudanças de estilos de vida. A obsessão pelo "novo" marcou a modernidade, o imaginário europeu ocidental desde o renascimento, e o colonialismo, que se afirmou frente ao Mundo Antigo 
- o Oriente (HAESBAERT, 2006, p. 19). A França é o país tido como o ponto onde houve muitos debates em torno do movimento de modernidade, entendido como revolucionário e progressista em contraponto às formas tradicionais não dispostas para realização de mudanças na esfera cultural, técnica e política. Daí, não poder confundir-se modernização e modernidade.

De acordo com Berman (1986, p. 14) Rousseau foi o "[...] primeiro a usar a palavra modernidade no sentido em que os séculos XIX e XX a usarão", como matriz de algumas tradições modernas, como é o caso da democracia participativa, mercado livre, revolução industrial, entre outras. No contexto de construção epistemológica, importa referir-se que a primeira fase de construção teórica de modernidade se centralizou nas disciplinas de Economia Política e de Sociologia.

Em termos reais, os estudos sobre modernidade se centram na explicação do seu significado nos processos históricos, bem como nas relações sociais que emanam das sociedades humanas. Sem pretender partir da gênese conceitual e muito menos da robustez explicativa dos estudiosos do tema, mas motivado pelo seu ideário, a nossa linha de análise epistemológica é a interpretação teórica das contradições que resultam da modernização.

De acordo com Domingues (2002), a teoria bem-sucedida para analisar os processos de transição socioeconômicos para a modernização, quer nos países do mundo capitalista rico, quer nos países de capitalismo tardio e pobre. O lume teórico identifica três caminhos possíveis para chegar à modernidade, tomando como ponto de partida a fase pré-industrial: 1) a via socialista revolucionária; 2) o movimento democrático e; 3) o caminho autoritário.

O primeiro caminho conduziu à construção de sociedades capitalistas e democráticas na Inglaterra, França e Estados Unidos. O movimento revolucionário burguês que aconteceu nesses países se manifestou por meio de alterações violentas determinando uma ruptura com a estrutura política e econômica do antigo regime, retirando, assim, os proprietários rurais do centro do poder político, dado que esses eram os principais responsáveis pelas decisões políticas no período da sociedade pré-industrial. No segundo caminho, foi institucionalizado outro grupo de capitalistas, sem recurso à violência, mas que foi capaz de adotar políticas reacionárias que conduziram ao regime fascista.

Esse processo de transformação das relações sociopolíticas e de produção não mudaram em nada a superestrutura do Estado e os detentores do poder político. Nesse sistema político, a nobreza fundiária detém o poder e o controle do Estado, pelo que se implanta uma administração de Bismark, dominada pela classe burguesa, o que Marx e Engels (2005) caracterizaram como a revolução 'a partir de cima'. 
O terceiro caminho foi o comunismo que se desenvolveu na Rússia e na China. As hipóteses concebidas por Lenin (1985) previam o desenvolvimento do capitalismo na Rússia seguindo duas vias, via prussiana e a outra do tipo norte-americano. A primeira, baseada em dois grupos, os grandes proprietários de terra e os pilares da antiga superestrutura e, a segunda, baseada na administração burguesa e ao latifundiário liberalmonárquico. A modernidade gestou as modernizações.

Quanto às questões econômicas, existem vários aspectos a serem levados em conta, mas o essencial é a produção de bens para a satisfação das necessidades do país, com reflexo direto sobre os principais indicadores macroeconômicos e microeconômicos. Por último, as questões sociais são referentes às implicações da modernização ao acesso dos recursos por parte da população, ou seja, componentes de equidade, justiça, gênero etc.

O processo de modernização do território tem seguido modelos de imposição, no que respeita aos padrões de consumo dos mais fortes para os mais fracos, como, ainda, na utilização dos meios cada vez mais modernos na cadeia produtiva, padronização os processos de produção, expropriando a terra dos camponeses, intensificando o uso de agrotóxicos e fertilizantes, entre outras ações consideradas inovações, incluindo a enculturação dos povos vistos como periféricos.

Desde o ano de 1987, Moçambique aderiu às reformas para reestruturação econômica que conferiram a possibilidade de passar a se beneficiar de fundos das instituições de Bretton Woods, Fundo Monetário Internacional (FMI) e Banco Mundial (BM) (MOSCA, 2010; 2015). No entanto, há autores que salientam que o BM tem implementado políticas que promovem o desemprego, dado que desestimulam economias locais. $O$ governo tem oferecido incentivos fiscais e concessão de terras ocupadas pelos camponeses ao setor privado estrangeiro para investimentos nos setores de agricultura, indústria e mineração (CASTEL-BRANCO, 2015; FREI, 2017, BATA, 2018).

O ProSAVANA-JBM se junta a outros programas ou iniciativas governamentais no âmbito de promoção de investimentos diretos estrangeiros (IDE). A facilitação do Governo já permitiu o estabelecimento de grandes empreendimentos econômicos, dos quais se destacam os seguintes: Kenmare Moma Mining (Mauritus) Lda, Vale, Rio Doce, Sazol, Green Lúrio Resorces, Jacaranda, Mozagrius, apenas para citar alguns exemplos, que já foram concedidos, pelo Governo de Moçambique, grandes extensões de terras para projetos de agronegócio e de mineração

De um modo geral, esses projetos são acusados pelos camponeses e pelas organizações da sociedade, de expulsarem os camponeses dos seus territórios. No caso particular do ProSAVANA-JBM, os camponeses são expulsos das terras que estão ao longo do corredor de Nacala, incluindo as que estão nas margens das bacias hidrográficas. 0 mesmo cenário se verifica nas regiões onde há registro de ocorrência de recursos 
minerais em Nampula, Tete, Manica, nas áreas declaradas como de conservação (Parques e Reservas) que são concessionadas às multinacionais ligadas à indústria turística.

A expropriação da terra dos camponeses pelos grupos poderosos constituiu o primeiro marco importante que deu origem ao que a literatura designa de "fronteira agrícola", enquanto as políticas liberais e neoliberais foram responsáveis pela apropriação da ciência pelo capital ajudando a intensificar os sistemas de produção por meio de uso de adubos químicos, pesticidas. Por conseguinte, a gênese de modernização tem a sua ligação com as sociedades ocidentais.

A dinâmica da modernização não tem sido a mesma ao longo do tempo e nos lugares. Na primeira fase a modernização significou a industrialização, que teve como repercussão o aumento da produção e produtividade e na perda de controle, pelos artesãos, de trabalho, conforme constatado na Revolução Industrial inglesa nos séculos XVIII e XIX.

Atualmente, o sentido de modernização é orientado aos modos de vida dominados pelo uso de tecnologias de informação e comunicação, a um maior fluxo de serviços financeiros, serviços das tecnologias e atividades ligadas à produção e utilização de informação. Vale enfatizar: a modernização tende a criar classes sociais antagônicas, como, também, configura novas condições de opressão e novas formas de lutas, no lugar das que existiram no passado. Nesse contexto, a modernização, uma vez apropriada pela burguesia, é um processo que se caracteriza por movimentos contraditórios

Do ponto de vista econômico, em Moçambique, a fase pré-capitalista foi caracterizada pelo controle do Estado relativo aos bens naturais e ao predomínio de sistemas de agricultura itinerante em pequenos lotes. Posto isto, a pergunta que se impõe é: em que direção as transformações tenderão?

\section{A GEOPOLÍTICA DA FRONTEIRA AGRÍCOLA}

A expansão da fronteira agrícola visa a acumulação da terra e/ou exercer o controle de terra como base essencial de produção de alimentos. Para compreensão desse movimento geopolítico, articulado pelo poder econômico, responsável pela definição e redefinição dos sentidos do uso do espaço agrário pela via hegemônica, torna-se importante fazer um enquadramento conceitual da definição de fronteira agrícola, do ponto de vista do seu significado e da operacionalidade.

A fronteira estabelece um limite entre territórios e nações. É usada pelo discurso dos países ricos perante a esfera geopolítica como lugar de proteção de Estados, representando, portanto, a autonomia e a soberania desses países perante os outros. Além desse sentido, considera fronteira “[...] o lugar de descoberta do outro e de desencontro" (MARTINS, 1996, p. 27). O sentido de fronteira é, ainda, aplicado para Estados- 
nações ou mesmo continentes, como refere-se (MARTINS, 1996, p. 25) que afirma que "as sociedades latinoamericanas ainda estão no estágio da fronteira". Nesse caso, usa-se a fronteira para caracterizar os territórios das sociedades latino-americanas, onde vários atores se envolvem em constantes disputas. De acordo com Martins (1996, p. 27), os conflitos envolveram índios, de um lado e os "civilizados" de outro; entre os grandes proprietários de terra, de um lado, e os camponeses pobres, de outro.

A consideração das sociedades latino-americanas, por exemplo, como estando em estágio de fronteira, entre as décadas de 1930 e 1950, teve como critério básico a densidade demográfica e a disponibilidade de terras baratas. As outras perspectivas de definição de fronteira são a sua função no sistema de produção capitalista e a de significação econômica da terra.

O movimento de fronteira - ou a fronteira como movimento - se enquadra na geopolítica contemporânea, que se constitui de forma articulada em dois sentidos, denominada por Haesbaert (2006) como front interno e front externo. Segundo o autor, o "front" interno ocorre nos Estados territoriais modernos, a partir do controle sobre os camponeses, da propriedade privada absoluta e incondicional e da soberania absoluta monarca. E o "front" externo se realiza mediante a conquista colonial, com a reinvenção moderna da escravidão para fins mercantis na América; enfim, com a invenção pela modernidade da colonialidade (HAESBAERT, 2006, p.18).

Ao observar o sentido externo do movimento da fronteira agrícola, tendo em conta os centros hegemônicos e os nós de distribuição, percebe-se que a sua tendência é cobrir e abarcar as áreas ainda remanescentes, localizados na África. No entanto, a maioria dos países africanos só foi instaurada a soberania dos Estados-nação, precisamente na década de 1970. A instauração de Estados-nação foi uma conquista parcial, não obstante, se constitui um movimento rico pelo seu significado na esfera sociopolítica e econômica. Em Moçambique, por exemplo, a instauração de Estado-nação foi declarada como símbolo de "libertação do homem e a devolução da terra aos legítimos donos que havia sido usurpada" pelos europeus,

De um modo geral, há convergência de opinião no sentido de que os processos de abertura de fronteiras agrícolas significam a incorporação de capital na terra, aumentando a renda. Esses processos fazem parte do modo de produção capitalista, que Rogério Haesbaert (2006) denomina de sistema-mundo moderno colonial. Com efeito, até essa década, o continente africano sofreu profundas alterações nas suas paisagens. Grupos étnico-linguísticos foram subdivididos do mesmo jeito que na Alemanha foram subdivididos em duas partes, durante a Guerra Fria, sem, no entanto, nenhuma indicação de possíveis caminhos para unificações. Embora não haja presença de objetos fixos iguais ao de murro de Berlin, o grupo Tsonga foi subdividido pelos Estadosnações das atuais Repúblicas de Moçambique, Zimbabwe, África do Sul e pelo Estado-nação do Reino de Suazilândia 
Os processos de reestruturação político-administrativa e socioeconômica dos territórios africanos e, particularmente, de Moçambique, encontram justificativas nas armadilhas dos eventos naturais, culturais, religiosas e econômicas. A irregularidade das chuvas, as desigualdades regionais produzidas pelo sistema capitalista colonial, o isolamento de algumas regiões, a heterogeneidade étnica, o autoritarismo dos governantes, o analfabetismo, incluindo interferências externas, são armadilhas que impedem aos reterritorializados o desfrute dos lugares. Esses problemas acabam justificando a abertura das fronteiras agrícolas como salvação.

A viabilização dos programas internacionais se deu a partir de fronteiras e integração do campesinato no sistema de produção capitalista. Isto significa que em alguns lugares a estratégia de Revolução Verde foi à abertura de fronteira e noutras foi à inserção do campesinato no sistema capitalista. Exemplo disto são os empréstimos concedidos e o direcionamento na aplicação dos recursos por parte do Banco Mundial como fica evidente a partir da figura 4.

Figura 4. Alocação de recursos e empréstimos do Banco Mundial em Moçambique. Elaboração: MACARINGUE, Ernesto Jorge.

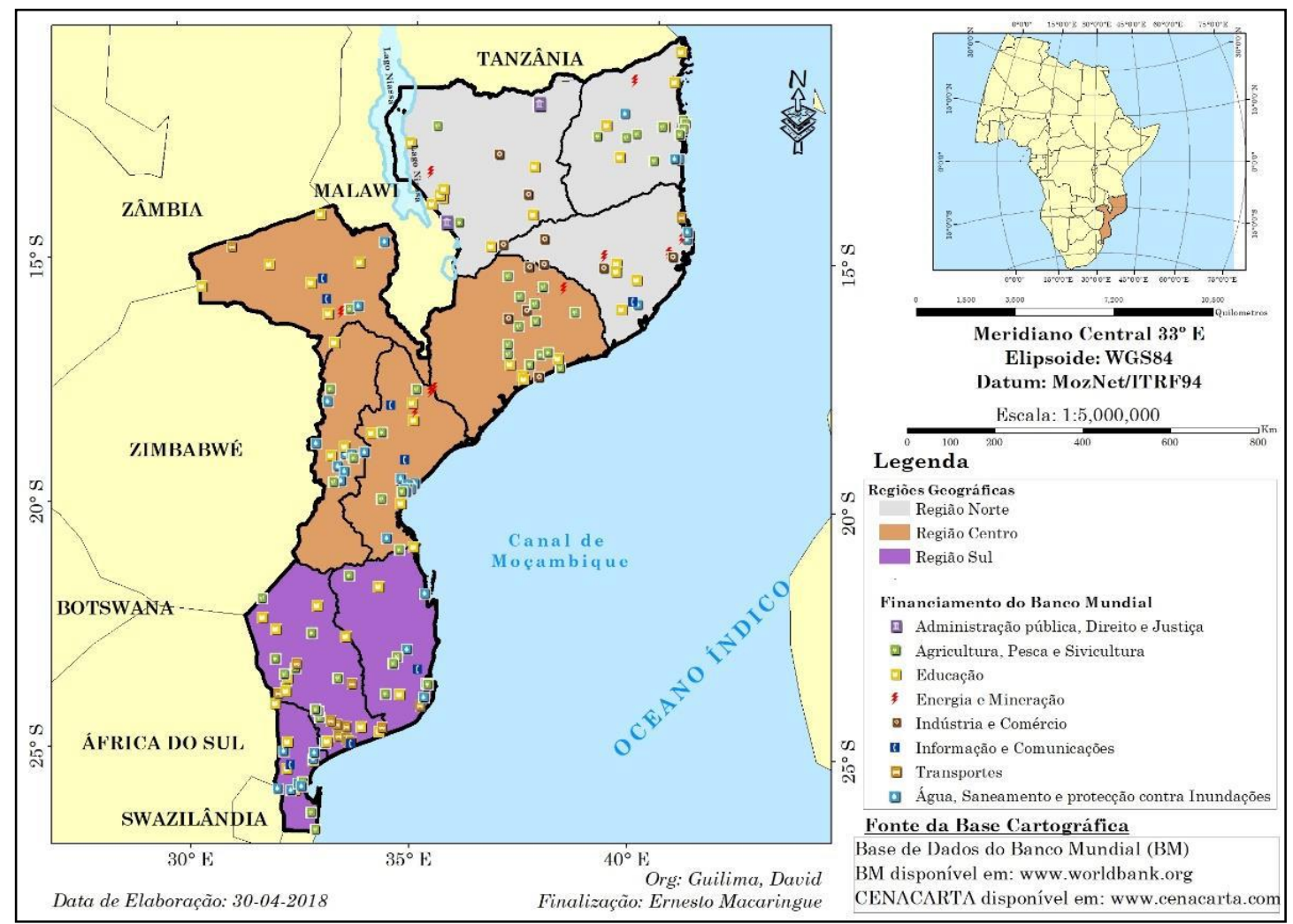

A evolução dos programas de Revolução Verde tem variado de lugar para lugar, em alguns países a sua viabilização ocorreu de forma rápida e em outros lugares há uma lentidão. Um dos prováveis motivos dessa variabilidade na dinâmica pode estar associado ao contexto da situação fundiária, por exemplo, em 
Moçambique, o programa Sasakawa Global 2000 tentou introduzir os pacotes de Revolução Verde no setor familiar. Essa experiência não durou muito tempo, dado que os camponeses não aderiram ao uso de adubos e fertilizantes químicos, aos agrotóxicos e/ou as sementes importadas.

Existe uma dose de evidências de que os pacotes de Revolução Verde não respondem aos problemas de economias internas se considerar que o contexto fundiário não permite a atribuição de um valor comercial, como também ocorre a falta de condições para o mercado de insumos e de fatores manufaturados pelo sistema capitalista.

Nessa lógica, as fronteiras seriam uma das vias a seguir para a viabilização da hegemonia política e econômica dos países capitalistas. Nesse contexto, a revolução verde constitui um mecanismo de dominação do setor da agricultura exercida pelas grandes corporações que passam a controlar a oferta de alimentos e de commodities no mundo. No plano ideológico, o capitalismo tem recorrido à sua "falsa capacidade" em abolir o trabalho forçado, como foi observado em relação à modernização da agricultura no Brasil.

\section{FOME EM MOÇAMBIQUE: A ARMADILHA DO AGRONEGÓCIO MEDIANTE O PROSAVANA-JBM}

A fome, os discursos da fome, a geração da fome e a ideologização da fome participam de quase todas as ações geopolíticas de expansão do agronegócio na África. E tem participado na ação geopolítica de modernização do distrito de Monapo. A fome é um fenômeno social em Moçambique e possui natureza social. Esse fato a torna uma armada que é mais fácil de ser utilizada para fins obscuros. Observando-se os organismos criados (Organização das Nações Unidas para a Alimentação e a Agricultura-FAO; Programa Mundial de Alimentos-PMA) e toda a mobilização que é feita, tanto para o debate dos temas relativos à fome, como para várias intervenções, nos faz questionar: o que constrói os determinantes da fome?

Paradoxalmente a situação de fome continua dramática, contrastando com os níveis de produção gerados no mundo. Segundo o último informe da FAO (2016), o número de pessoas padecendo de fome no mundo aumentou em 11\%, ou seja, de 777, passou para 815 milhões. O maior desafio, de acordo com a FAO (2016), é "assegurar que uma população em crescimento tenha alimentos à sua disposição para satisfação das suas necessidades nutricionais"?

No caso específico de Moçambique, as estimativas do INE (2016) apontam que em 2012, 54\% da população padeceu de fome. A fome em Moçambique ocorre, frequentemente, entre os meses de julho a dezembro. Pode-se até se afirmar que tornou-se "normal" ouvir notícias de ocorrência, em áreas rurais e nas periferias urbanas, usando-se narrativas de "bolsas" de fome. É necessário informar que a fome não é a única calamidade que ciclicamente tem flagelado Moçambique enquanto um país pobre 
O governo de Moçambique necessita de apoios externos para resolver os problemas causados pela fome (desnutrição, delinquência, etc.), bem como de outras mazelas que transcendem as capacidades dos cidadãos. Aliás, o governo precisa de apoios externos e de outras formas de apoios indiretos, como é o caso das intervenções de organizações não governamentais e setor privado, que canalizam donativos e subvenções face ao déficit do orçamento público.

Além de apoios para o enfrentamento das questões associadas à fome, as ajudas são também canalizadas aos setores de educação, saúde pública, infraestruturas (estradas, ferrovias, pontes, redes de rega e drenagem). Só para se ter ideia da gravidade das debilidades do país, dados mais recentes indicam que mais de 2/3 da população estudantil está à margem do sistema formal do ensino (INE, 2014). Ainda, de acordo com a Organização Mundial de Saúde (OMS), em 2014 a expectativa de vida em Moçambique estava fixada em 53 anos. A fraca cobertura da rede sanitária, a relação médico/povo é preocupante. As doenças preventivas, tais como a malária e as diarreias são as responsáveis por elevado índice de mortalidade. Relativo à economia, o país se debate com a descapitalização financeira. O que significa que não existe capacidade interna para novos investimentos, ou ainda, para melhorar os já existentes. A produção total do país é muito baixa. Em 2016, o produto interno per capta fixou-se em 382,07 dólares norte-americanos.

No plano tecnológico não existe nenhum sinal que mostre tendência de alteração dos meios técnicos rudimentares, como, também, de práticas culturais. O uso de meios manuais e a queima de biomassa são exemplos claros de meios rudimentares e práticas culturais ainda bem visíveis em todo o país. Se no plano dos meios técnicos e das práticas não se registra modificações, o mesmo acontece no que concerne à propagação de espécies de cultivos de outras partes do mundo, como é o caso da cultura de soja. Além da propagação, há também um processo de massificação do cultivo de hortícolas e criação de aves em granjas.

Paradoxalmente, o país detém um histórico na criação de espécies animais, como os gados bovinos, os ovinos e os suínos, mas são poucos os agregados familiares que criam animais, sobretudo gado bovino. Nos poucos casos em que existe a criação de animais, não há nenhuma estrutura de suporte de atividades de índole pecuário. O ProSAVANA-JBM, em Moçambique, é um exemplo evidente de um ato que não é intrínseco, mas de algo planejado com o propósito de imprimir mudanças, todavia, como foi salientado, numa perspectiva de controle da produção de alimentos para sanear a economia dos países ricos.

Ai discorrer sobre a história econômica de Moçambique, constata-se que desde 1975 até a atualidade dois programas de desenvolvimento agrários foram implementados - PROAGRI I e II. No percurso de 43 anos de formação do Estado-Nação, no período compreendido entre 1976 a 1992 (dezesseis anos consecutivos), o país esteve mergulhado num ambiente de conflitos armados violentos. Os prejuízos causados por esses conflitos ultrapassam os que sucederam durante a luta pela independência. Há quem aponta o dedo em fatores externos da sociedade moçambicana como 
tendo sido as principais razões desse ambiente de conflitos armados. Sobretudo, as divergências ideológicas no seio de uma sociedade que tem suas raízes em três traços culturais: africana, europeia e asiática.

Neste estudo, parte-se do pressuposto de que o conflito armado dos dezesseis anos faz parte da conjuntura internacional, que é permeado pelas contradições do sistema capitalista: a divisão administrativa africana é na realidade um problema que está na origem de conflitos que tendem ser de carácter étnico; as relações impostas pelos processos de colonização também estabeleceram clivagens de disputas de poder. A complexidade dos povos africanos - o caráter disperso das aldeias e as diferentes maneiras de concepção do mundo que rodeiam os povos - cujos limites são as etnias, são os elementos que estão por detrás dos conflitos armados em Moçambique, que Portugal utilizou como estratégia para exercer a sua dominação.

Ao prestar atenção apenas no setor da agricultura, deparamos com os seguintes fatos: em todo o país há mais de 4 milhões de explorações agropecuárias; dessas explorações, 99\% representam a agricultura camponesa de autoconsumo; em termos de força de trabalho que essa agricultura mobiliza, aponta-se que o setor agrário concentra 95\% da força de trabalho em todo o país; projeções do Banco Mundial (BM), em 2016, sobre o comportamento da economia, apontaram para uma desaceleração da taxa de crescimento que, neste momento, está fixada em $3 \%$ ao ano. Em nível de segurança alimentar, o Fundo das Nações Unidas para Alimentação (FAO), no Programa da FAO para Moçambique, refere que $43 \%$ das crianças com menos de cinco anos sofrem de má nutrição crônica, devido à pobreza das dietas alimentares. Refere-se, ainda, que $18 \%$ das crianças têm peso abaixo da média, havendo crianças nas zonas rurais com duas vezes menos peso que as crianças que vivem nas zonas urbanas.

Estudos que se dedicam à análise dos fatos socioeconômicos estão bipolarizados em justificativas que aludem aos problemas que causam a fome em Moçambique. Enquanto uns enfatizam problemas ou fatores conjunturais, outros dão primazia aos fatores estruturais e há, ainda, outros que destacam a questão de atitudes das pessoas sistematicamente flageladas pela fome. Compreendem-se por fatores conjunturais os constrangimentos que são derivados de situações que estão fora do controle dos afetados, como a crise alimentar mundial derivada da subida de preços dos alimentos. Enquanto os estruturais são as vicissitudes que resultam do contexto das políticas socioeconômicas. A questão relativa às atitudes é concernente às escolhas que são feitas pelas pessoas. Há uma tendência crescente de se responsabilizar os afetados pela fome, sustentada na ideia de que a situação é consequência das suas próprias decisões, justificando as que não têm sido racionais.

Ao concentrarmos para entender as formas de manifestação da fome, constatamos que ela se distingue em três dimensões escalares, nomeadamente local, nacional e geopolítico. Compreende dimensão local a fome muito bem localizada espacialmente em relação aos sujeitos afetados. São o caso das bolsas de fome que são pontos, regiões em que os afetados podem ser famílias e comunidades inteiras que veem suas reservas alimentares se esvaziar como resultado de más colheitas devido às calamidades naturais (seca, tempestades, inundações, ciclones) e conflitos político- 
militares. A dimensão nacional seria situações em que o fruto do trabalho não é traduzido por rendimentos correspondentes às necessidades do país e, por último, a dimensão geopolítica compreenderá os problemas causados pelas relações no poder das instituições e/ou dos Estados.

A dimensão geopolítica comanda os acordos nos quais impelem o processo de modernização pela via do controle das terras. Tendo em vista os últimos contornos nos dois anos anteriores - 2016 a 2017 - no capítulo das relações multilaterais entre o Governo de Moçambique (GdM) com o Fundo Monetário Internacional (FMI) e o Banco Mundial (BM), caracterizadas por uma deterioração pelo fato de o GdM ter contraído empréstimo à revelia dessas duas instituições financeiras, nos conduz a dizer que essas relações têm outros interesses que estão alheios à maioria da população.

Uma das consequências das relações tensas instaladas foi a configuração do país na lista dos países não elegíveis para investimentos estrangeiros. Na figura 5, são apresentados alguns dos países e seus projetos de exploração dos recursos de Moçambique.

Figura 5. Colonização do continente Africano no século. Elaboração: MACARINGUE, Ernesto Jorge.XXI.

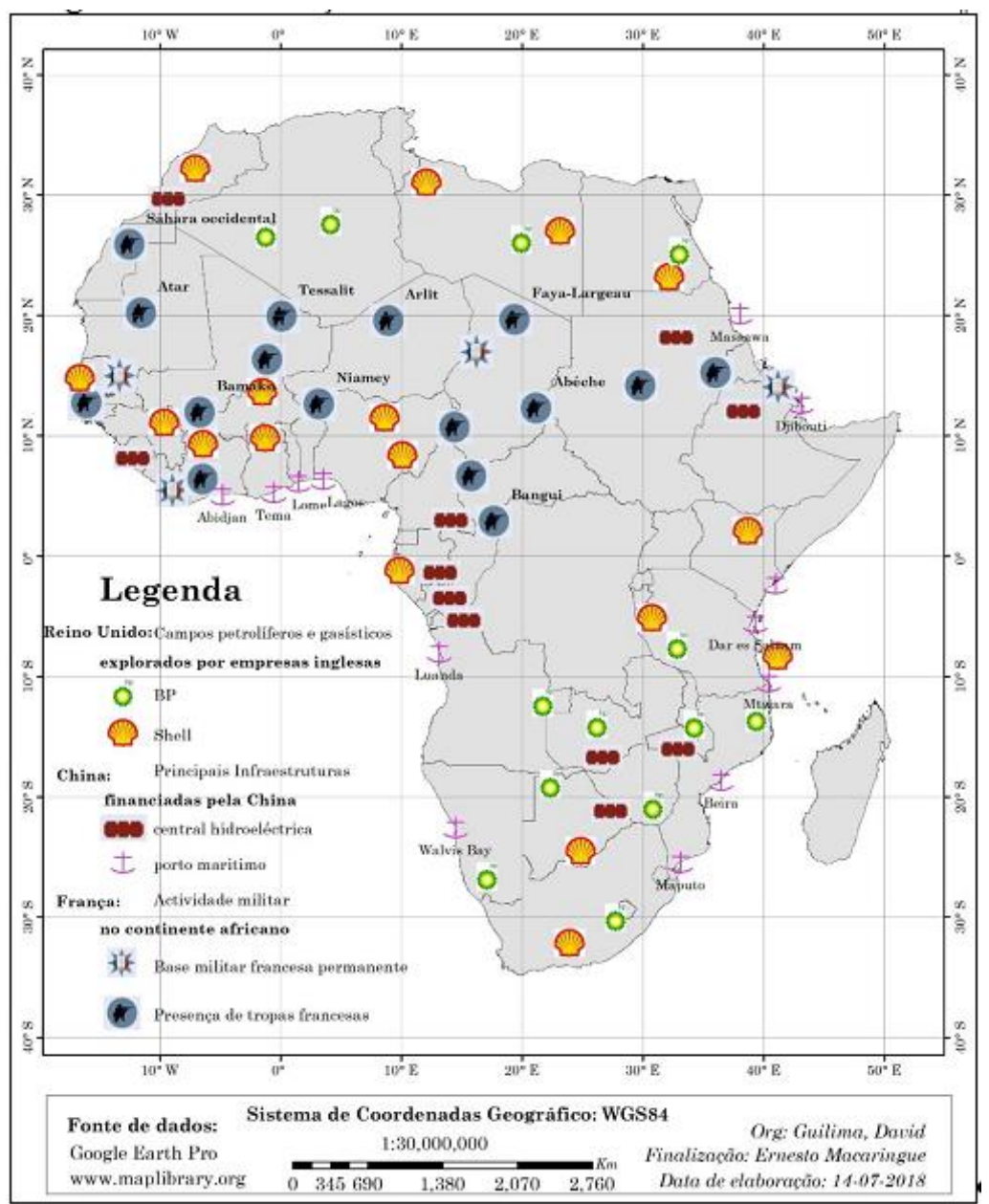


Por outro lado, desde 2016, o FMI e os parceiros internacionais membros do FMI deixaram de prestar apoio ao Orçamento Geral do Estado (OGE). Este fato tem agravado os termos de troca entre a moeda nacional com as dos países mais ricos, com que se mantêm relações comerciais mais estreitas. Paradoxalmente, os interesses econômicos dessas duas instituições financeiras, incluindo os de outras instituições, como é o caso do Banco Africano de Desenvolvimento (BAD), estão ativos.

Empresas, como as mineradoras Vale S.A, Kenmare, Anadarko Petroleum e Sasol, que exploram recursos energéticos existentes no país, tendem a deter o monopólio de exploração de bens estratégicos na atualidade e impor o controle corporativo dos territórios em Moçambique.

Como se vê, os acordos e os projetos de modernização do território e do espaço agrário são frentes geopolíticas. O ProSavana é uma dessas frentes. O discurso de sanear a fome aumentando a produção e a produtividade, a ideologização de modernizar como sinônimo de progresso social; e o controle das terras férteis e dos recursos naturais operam armadilhas na produção de alimentos e na produção de commodities. O exemplo de abertura de fronteira no Brasil, tal como o Cerrado, adverte-nos para os problemas vindouros, como a concentração de capital e da terra; a deterioração do solo; o envenenamento da água e especialmente a força política do setor agrarista. Vale, pois, questionar esse modelo compreendendo a dimensão política do processo modernizante - e seus fins. Isso não impede de pensar a incrementação das forças produtivas, a melhor forma de repartir os bens produzidos, a importância da cooperação internacional.

\section{CONSIDERAÇÕES FINAIS}

O ProSAVANA-JBM é um exemplo vivo de um cenário geopolítico, cujo o objetivo é a mercantilização de alimentos e a abertura de uma nova fronteira agrícola em Moçambique. Como se viu, na sua concepção não se contou com a participação dos "ditos grupos alvos": os camponeses. O seu mote foi a assistência técnica imputada do pelo Estado de Moçambique, pelos governos do Brasil e do Japão. Diz-se, na figura discursiva e ideológica, que seu objetivo é melhorar a competitividade do setor rural em dois vetores: segurança alimentar e geração de excedentes para exportação.

Contudo, as estratégias adotadas incrementam a produtividade por meio da assistência técnica formando as bases do agronegócio no país, fazendo sucumbir a produção camponesa. Tanto o objetivo do ProSAVANA-JBM, como os das estratégias escolhidas, não deixam nenhuma dúvida de que estamos perante um projeto em que se pretende a "modernização do setor agrário". Quando se diz "melhorar a competitividade do setor rural da região" e "apoio técnico à agricultura orientada para o agronegócio", fica 
esclarecido que a intenção é transformar o espaço agrário, dando-lhe um destino geopolítico, ao invés de uma solução interna.

O discurso do Estado de alavancamento de mudanças estruturais escamoteia o real sentido do projeto. Por isso, o programa, estrategicamente, não fala de modernização, mas de condições de vida da população residente na região norte de Moçambique. Subentende-se que os fins pretendidos são novos modelos de produção no seio da vida camponesa. Tal como a experiência brasileira de modernização agrícola do Cerrado, ao filiar a agricultura ao negócio de alimento controlado pelas grandes corporações, ocorre, está ocorrendo e ocorrerá - uma desarticulação das comunidades. Esses modelos preconizam a ascensão dos camponeses para uma nova categoria social, a de agricultores familiares, que passarão a ser competitivos nos seus espaços, como também produzirão bens para exportação.

De fato, a pesquisa revelou que a modernização da agricultura se refere às mudanças operadas nos sistemas que regem a terra, mas a maior parte de literatura da questão agrária, em Moçambique, trata-a apenas como transformação do componente técnico. Nesse contexto, vale dizer que a proposta de modernização do espaço agrário e da agricultura para sanear o problema de fome ou para resolver os problemas de insegurança alimentar, em Moçambique, só pode ser compreendida a partir de uma análise que abarca a totalidade dos aspetos acima referidos, nomeadamente a questão agrária, a questão agrícola e outros componentes sociais, como as relações de produção.

Em suma, mostramos que a ação geopolítica dos projetos em curso possui uma justificativa ideológica baseada na eliminação da fome. Mostramos também ser necessária a análise espaço/temporal de Moçambique e de seus componentes naturais. Vimos, ainda, o modo pelo qual o Estado moçambicano tem agido junto aos organismos que dão poder aos países capitalistas hegemônicos.

\section{REFERÊNCIAS}

BATA, Eduardo Jaime. Entre estatais e transnacionais, "quantos ais": efeitos espaciais dos Megaprojetos de mineração do carvão em Moatize, Moçambique. Goiânia. 565 f. Tese (Doutorado em Geografia) - Universidade Federal de Goiás. Instituto de Estudos Socioambientais, Goiânia, 2018.

BERMAN, Marshall. Tudo que é sólido desmancha no ar: a ventura da modernidade. Tradução de Carlos Felipe Moisés e Ana Maria L. Ioriatti. São Paulo: Editora Schwarcz, 1986.

CASTEL-BRANCO, Carlos Nuno; MASSINGUE, Nelsa; MUIANGA, Carlos. (Org.). Desafios para Moçambique. Maputo: IESE, 2015. DOMINGUES, José Maurício. A Dialética da modernização conservadora e a nova história do Brasil. Revista de Ciências Sociais, Rio de Janeiro, v. 45, n. 3, p. 459-482, 2002.

FAO; IFAD; WFP. The State of Food Insecurity in the World 2015. Meeting the 2015, international hunger targets: taking stock of uneven progress. Rome: FAO, 2015.

FREI, Vanito Viriato Marcelino; PEIXINHO, Dimas Morais. Do Brasil à Moçambique, uma travessia, um índico: sistemas de produção de caju e dinâmicas socioespacial no distrito de Angoche. Goiânia: Kelps, 2016. 
FREI, Vanito Viriato Marcelino. No país do mano Muça, eu sou carvão: implicações socioterritoriais dos megaprojetos de mineração nas comunidades locais da província de Nampula. Goiânia. 412 f. Tese (Doutorado em Geografia) - Universidade Federal de Goiás. Instituto de Estudos Socioambientais, Goiânia, 2017.

HAESBAERT, Rogério. Des-territorialização e Identidade: a rede gaúcha no nordeste.Niterói: EDUFF, 1997.

HAESBAERT, Rogério; GONÇALVES, Carlos Walter Porto. A nova des-ordem mundial. São Paulo: Editora UNESP, 2006.

HARVEY, D. O enigma do capital: e as crises do capitalismo. Trad. João Alexandre Peschanski. São Paulo: Boitempo, 2011.

INE. Censo Agropecuário CAP 2009-2010: Resultados Definitivos - Moçambique. Maputo, 2011.

INE. Panorama Sócio-Demográfico de Moçambique. Maputo, 2013.

LENIN, Vladimir Ilich. $\mathbf{O}$ desenvolvimento do capitalismo na Rússia: o processo de formação do mercado interno para a grande indústria. Tradução de Jose Paulo Netto. 2. ed. São Paulo: Nova Cultural: 1985.

MARTINS, José de Souza. Fronteira: a degradação do Outro nos confins do humano. 2ạ ed. São Paulo, Contexto: 2014.

MARTINS, José de Souza. $O$ tempo da fronteira retorno à controvérsia sobre o tempo histórico da frente de expansão e da frente pioneira. In: Tempo Social, São Paulo, v. 8, n. 01, p. 25-70, maio, 1996.

MARX Karl; ENGELS Friedrich. Manifesto Comunista. Tradução de Soveral Martins. Coimbra: Centelha, 1974.

MARX Karl; ENGELS Friedrich. A Ideologia Alemã, 10 capítulo: seguido das Teses sobre Feuerbach. Tradução de Silvio Donizete Chagas. São Paulo: Centauro, 2002.

MOÇAMBIQUE, MASA. Anuário de Estatísticas Agrárias 2015. Maputo, 2015.

MOÇAMBIQUE. Plano estratégico de desenvolvimento do sector agrário 2011-2020. Maputo: MASA, 2011.

MOSCA, João. Políticas agrárias e mudanças na agricultura de Moçambique (1975-2009). In: MOSCA, João. (Coord) Contributos para o Debate da Agricultura e do Desenvolvimento Rural. Maputo, Escolar Editora, 2012.

MOSCA, João. Evolução da agricultura moçambicana no período pós-independência. Lisboa: Universidade Técnica de Lisboa, 1996.

PAULINO, Eliane Tomiasi. Territórios em disputa e agricultura. In: FABRINI, João Edmilson; PAULINO, Eliane Tomiasi (Org.).

Campesinato e territórios em disputa. 1‥ ed. São Paulo, Editora Expressão Popular, 2008.

PROSAVANA. Elaboração do plano diretor do desenvolvimento agrícola no corredor de Nacala: nota conceitual. Maputo. 2013. Acessado em: 3 jun. 2014.

SANTOS, Milton. Da totalidade ao lugar. São Paulo: Editora da Universidade de São Paulo, 2005.

SANTOS. A Natureza do espaço: Técnica e Tempo, Razão e Emoção. São Paulo: Edusp, 2002.

SANTOS. Técnica, Espaço, Tempo. 5. ed. São Paulo: Edusp, 2013.

SANTOS. Economia espacial: críticas e alternativas. Tradução de Maria Irene de Q. F. Szmrecsanyi. São Paulo: HUCITEC. 1979. 